
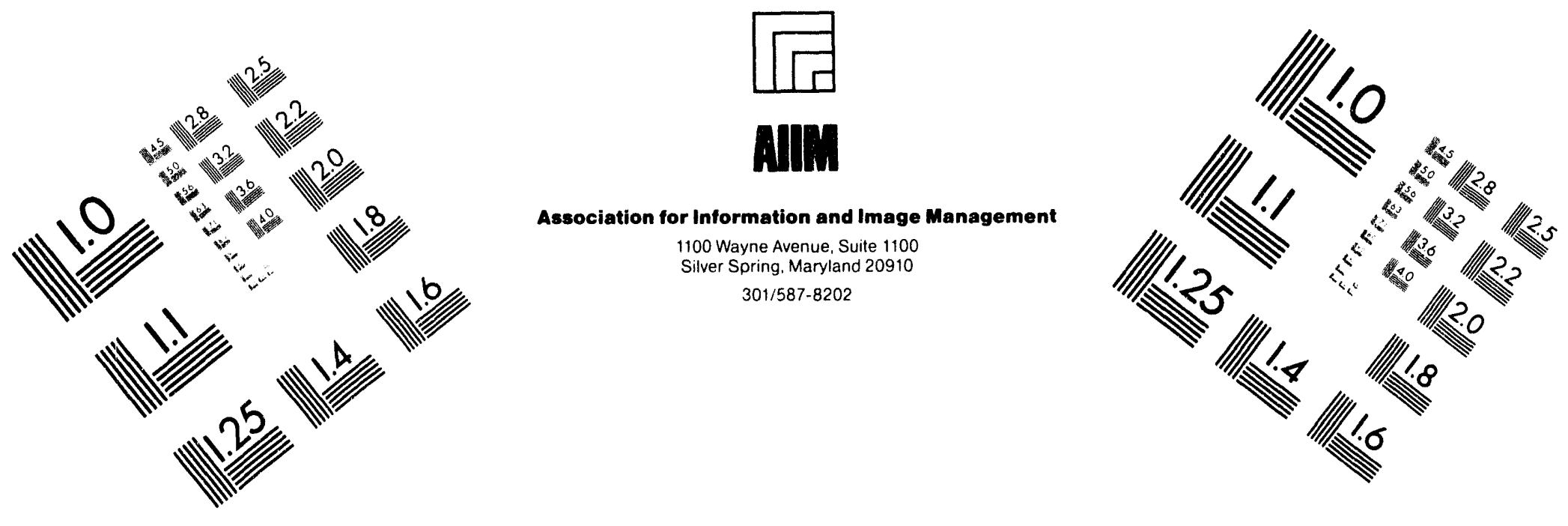

\title{
Centimeter
}

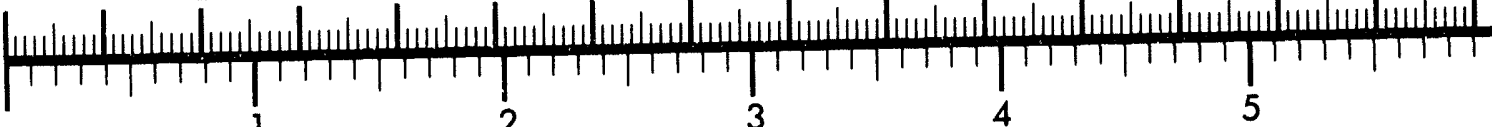
Inches

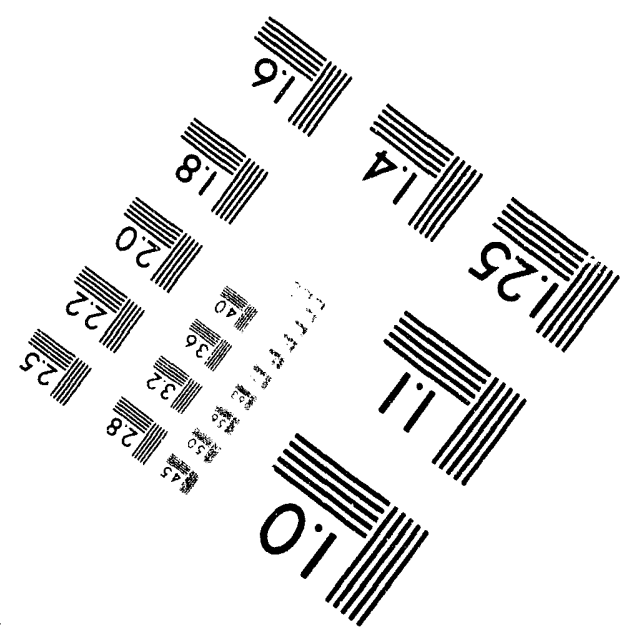

MANUFACTURED TO AIIM STANDARDS BY APPLIED IMAGE, INC.

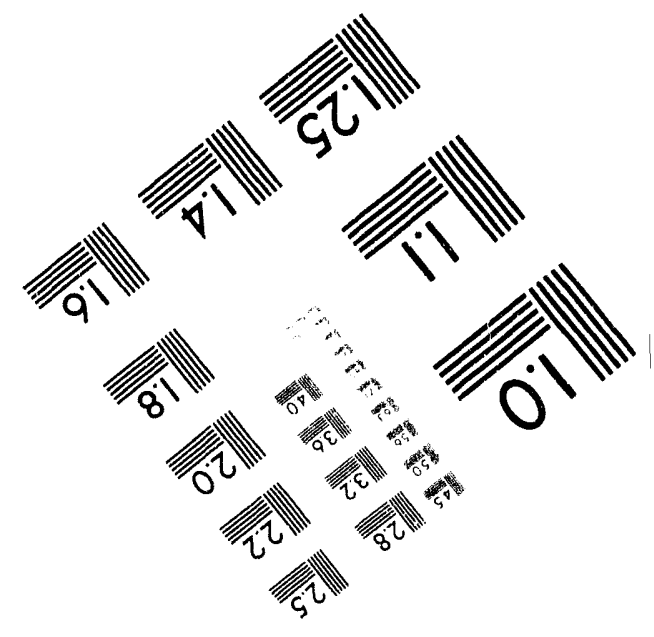



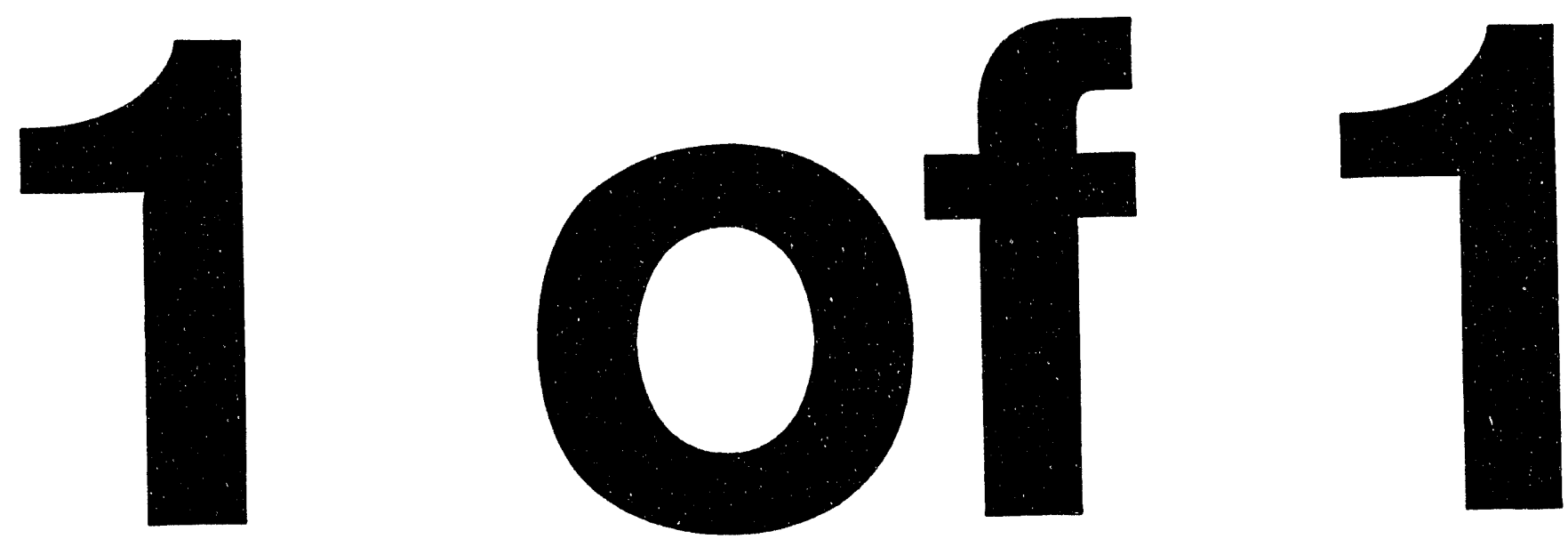


\title{
ANK/TD/CP. - 816.60 \\ Conf $-940664--19$ \\ Paper
}

\section{MHD PRESSURE DROPS AND THERMAL HYDRAULIC ANALYSIS FOR THE ITER BREEDING BLANKET DESIGN*}

\author{
by \\ THANH Q. HUA \\ Fusion Power Program \\ Technology Development Division \\ Argonne National Laboratory \\ Argonne, IL 60439 USA \\ YOUSRY GOHAR \\ ITER Garching Joint Work Site \\ Max-Planck-Institut fur Plasmaphysik \\ D-85748 Garching bei Munchen \\ GERMANY \\ DISCLAIMER
}

\begin{abstract}
This report was prepared as an account of work sponsored by an agency of the United States Government. Neither the United States Government nor any agency thereof, nor any of their employees, makes any warranty, express or implied, or assumes any legal liability or responsibility for the accuracy, completeness, or usefulness of any information, apparatus, product, or process disclosed, or represents that its use would not infringe privately owned rights. Reference herein to any specific commercial product, process, or service by trade name, trademark. manufacturer, or otherwise does not necessarily constitute or imply its endorsement, recommendation, or favoring by the United States Government or any agency thereof. The views and opinions of authors expressed herein do not necessarily state or reflect those of the United States Government or any agency thereof.
\end{abstract}

June 1994

Submitted to the Third International Symposium on Fusion Nuclear Technology, University of California at Los Angeles, June 27 - July 1, 1994.

* Work supported by the United States Department of Energy/Office of Fusion Energy, under Contract No. W-31-109-Eng-38.

CISTRIBUTION OF THIS DOCUMENT IS UNLIMITED

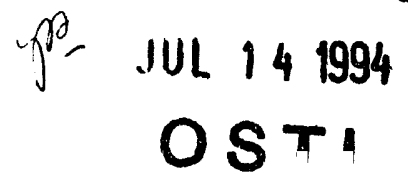




\title{
MHD PRESSURE DROPS AND THERMAL HYDRAULIC ANALYSIS FOR THE ITER BREEDING BLANKET DESIGN*
}

Thanh Q. Hua

Argonne National Laboratory

9700 South Cass Avenue

Argonne, Illinois 60439

U.S.A.

\author{
Yousry Gohar \\ ITER Garching Joint Work Site \\ Max-Planck-Institut fur Plasmaphysik \\ D-85748 Garching bei Munchen \\ GERMANY
}

\begin{abstract}
The breeding blanket design of the International Thermonuclear Experimental Reactor (ITER) is a self-cooled liquid lithium system with a vanadium structure. Electrical insulation of the coolant channel surfaces from the liquid metal is required to reduce the magnetohydrody namic (MHD) pressure to less than $1 \mathrm{MPa}$. Insulation is provided by AIN coating at the channel surfaces in contact with lithium. MHD pressure drop and thermal hydraulic analysis of the blanket design is carried out subject to pressure, temperature, and stress considerations. Design windows relating the lithium flow velocity, MHD pressure, and structural temperature are formulated. The requirements of the insulator coating and characterization of the coating effectiveness are presented. Effects on the MHD pressure drop due to uniform cracks through the coating layer is also analyzed.
\end{abstract}

* Work supported by the U.S. Department of Eriergy, Office of Fusion Energy, under Contract No. W-31-109-Eng-38. 


\section{Introduction}

Design of a self-cooled breeding blanket has been pursued by the ITER Joint Central Team [1] to satisfy the technical objectives of the Extended Performance Phase. The blanket structure is made of vanadium alloy (V5Cr5Ti) and the coolant/breeder is liquid lithium. Vanadium is considered because of its superior thermal and mechanical properties at high temperatures, high neutron fluence capability, low activation, and good compatibility with liquid lichium. Lithium is the preferred choice of coolant/breeder because of its good tritium breeding capability, good thermal conductivity, and low mass density.

A key design consideration, and quite often a constraint, of a liquid metal blanket is the magnetohydrodynamic (MHD) pressure. Allowable pressure is governed by the tolerable mechanical stresses on the first wall, and /or other blanket structural components. The factors determining the MHD pressure drop include flow velocity, duct dimensions, magnetic field strength, coolant path length, and electrical conductivity of the liquid metal and the coolant channel walls. Under ITER operating and geometric conditions the MHD pressure drop would be prohibitively high (> $30 \mathrm{MPa}$ ) if the coolant channels walls are electrically connected to the liquid metal. To reduce the MHD pressure to a manageable level ( 1 MPa) electrical insulation between the walls and the liquid metal is required. Insulation can be achieved by a thin insulator coating at the wall surfaces in contact with lithium. Among several coating materials being considered ( $\mathrm{AlN}, \mathrm{CaO}, \mathrm{MgO}$ ), $\mathrm{AlN}$ is the leading choice for ITER blanket application. 
This paper focuses on the MHD and thermal hydraulic aspects of the breeding blanket which has a simple poloidal flow design. Only the inboard blanket is analyzed because of its more stringent conditions in higher toroidal magnetic field and less flow volume than the outboard blanket. Once an inboard blanket design is established, an outboard design is guaranteed, at least for one that is similar to the inboard. The MHD/thermal hydraulic analysis assumes perfect insulation by the AIN coating. Requirements and characterization of coating effectiveness are defined in terms of the coating parameters and blanket design conditions. In addition, the effects on MHD pressure drop due to uniform cracks through the coating are analyzed.

\section{Blanket Configuration and Design Criteria}

A simple poloidal flow design is proposed for the ITER breeding blanket. The blanket consists of segments that can be installed and removed through the vertical ports between the toroidal field (TF) coils. Each segment has several modules. The modules form a continuous toroidal structure and they are connected to the back plate. The inboard blanket has 48 segments, each segment has 3 modules. The radial depth of the module is $45 \mathrm{~cm}$, which includes a $5-\mathrm{mm}$ vanadium first wall and a $7-\mathrm{cm}$ thick vanadium back plate. A $5-\mathrm{cm}$ thick beryllium zone is integrated in the lithium supply channels for neutron multiplication and improved blanket shielding. Also, a 12-cm thickness tungsteil carbide zone is used in the lithium return channels to enhance the blanket shielding performance. Figure 1 shows the cross section of a segment. Flow servicing for each module is provided by an inlet and outlet pipe, $30-\mathrm{cm}$ in diameter, connecting to a supply and return manifold, both located at the top. 
The emphasis of the design [2] is to limit the peak vanadium first wall temperature to less than $500^{\circ} \mathrm{C}$ and total pressure drop to less than $1 \mathrm{MPa}$. Although vanadium can tolerate higher temperature, the $500^{\circ} \mathrm{C}$ limit is conservatively chosen to allow sufficient margin during power excursions and additional safety margin for irregularities in engineering details. Higher temperature limit is possible if it is needed. Radial temperature difference between the first wall and backwall is limited to less than $100^{\circ} \mathrm{C}$, which can also be relaxed to $150^{\circ} \mathrm{C}$ if needed, to minimize the thermal stress in the modules.

\section{MHD and Thermal Hydraulic Analysis.}

MHD pressure arises from the interaction of electric currents in the liquid metal with magnetic field. Electric currents are induced in the liquid metal when it is circulated in the presence of an externally applied transverse magnetic field. These currents must form a close loop either through the walls if they are conducting or through the thin boundary layers, known as Hartmann layers if the walls are electrically insulated. The magnitude of these currents, and the corresponding MHD pressure, is inversely proportional to the resistance of the electric circuit. Because the Hartmann layers have very large electrical resistance, much larger than the wall resistance, the electrical currents and the MHD pressure in insulating wall ducts are significantly reduced.

For fully developed flow in a rectangular duct with electrically-insulated wall, the MHD pressure drop is given by

$$
\Delta \mathrm{P}=\mathrm{M}^{-1} \sigma \mathrm{UB}^{2} \ell
$$


where $\sigma$ is the liquid metal's electrical conductivity, $U$ is the average flow velocity, $B$ is the magnetic flux density, $\ell$ is the flow path length, and $M$ is the Hartmann number. The Hartmann number is

$$
\mathrm{M}=\mathrm{Ba}\left(\frac{\sigma}{\mu}\right)^{1 / 2}
$$

where $\mu$ is the liquid metal's viscosity, and a is one half the channel height in the direction parallel to $B$. For the current design, $M \approx 90000$.

The flow in the long poloidal coolant ducts is approximately fullydeveloped so MHD pressure can be simply computed by Eq. (1). The flow in the inlet/outlet pipes and manifolds, has three-dimensional distribution. The MHD pressure is significant and calculation is rather complex. Three-dimensional effects arise from the spatial variation of the magnetic field or the duct cross section. The three-dimensional MHD computer code for insulating circular ducts [3] developed at Argonne National Laboratory is used to model the flow and compute the MHD pressure in the inlet/outlet circular pipes region.

At present, there is no computer code to model an insulating wall manifold feeding an array of coolant ducts in the plane parallel to the field. Until the development of such a code is completed, estimate of pressure drops for the manifolds can be obtained based on current MHD knowledge and experience. Asymptotic analysis of MHD flow in an insulated circular duct whose cross section expands or contracts along the flow axis in uniform magnetic field [4] indicates that the three-dimensional MHD pressure is of the order of 
$\mathrm{M}^{-1 / 2} \sigma \mathrm{UB}^{2} \mathrm{a}$. Similar results were found from numerical modeling of flow in uniform cross section pipe but with a varying magnetic field [3]. In addition, analysis of straight duct with conducting wall in varying magnetic field [5] and conducting manifold in uniform field [6] also give comparable three-dimensional pressure between the two cases. Therefore the code for insulating circular pipe is used to generate data which approximate the pressure drops in the manifolds.

Figure 2 shows the computed MHD pressure as a function of $\mathrm{M}^{-1 / 2}$ for rapidly varying magnetic fields. The code results are fitted to give the following empirical relation:

$$
\Delta \mathrm{P}_{3 \mathrm{D}}=0.5 \mathrm{M}^{-1 / 2} \sigma \mathrm{UB}^{2} \mathrm{a}
$$

Equation (2) is used to estimate the pressure drop in the inlet/outlet manifolds where $\mathrm{M}$ is the Hartmann number in the manifold based on the average characteristic length a.

The total MHD pressure is the sum of pressures in the inlet/outlet pipes, manifolds, and poloidal coolant channels. Figure 3 shows the total MHD pressure drop and pumping power for the inboard blanket for an average velocity (in the supply channels) in the range of $0.75-2.5 \mathrm{~m} / \mathrm{s}$. The pressure drop is less than 1 $\mathrm{MPa}$ in all cases studied. The pressure drop in the poloidal coolant channels account for about $45 \%$ of the total.

For heat transfer calculations, slug flow is assumed for the fully developed flow in the poloidal coolant ducts. The three-dimensional heat transfer code [7] is used in this analysis. The nuclear heating radial distribution in the blanket, shown 
in Fig. 4, is provided by neutronic analysis. Fusion power of $1800 \mathrm{MW}$ is chosen to allow a $20 \%$ power excursion from the nominal $1500 \mathrm{MW}$ operating power. Therefore, the results presented here correspond to average neutron wall loading of $1.2 \mathrm{MW} / \mathrm{m}^{2}$ and average surface heat flux of $0.24 \mathrm{MW} / \mathrm{m}^{2}$. Inlet coolant temperature at $250^{\circ} \mathrm{C}$ is prescribed.

Figure 5 shows results of peak vanadium first wall temperature, back plate temperature, and the bulk exit temperature. The peak temperature limit is satisfied even at low velocity $(0.75 \mathrm{~m} / \mathrm{s})$, but what would preclude the low flow rate consideration is the radial temperature difference between the front and the back as can be seen in Fig. 6. To maintain a radial temperature difference of less than $100^{\circ} \mathrm{C}$ at every poloidal elevation, flow velocity of $2 \mathrm{~m} / \mathrm{s}$ or more is needed. Table 1 presents the engineering parameters for the case of $2 \mathrm{~m} / \mathrm{s}$.

\section{Electrical Insulator Requirements}

A feasible insulator coating material must meet the following minimum requirements:

- Thermodynamically stable at elevated temperature, up to $600^{\circ} \mathrm{C}$.

- Chemically compatible with lithium and the structural material.

- Capable of self-healing in-situ to repair any cracks or faults.

- Sufficiently high electrical resistivity (higher than $10^{5} \Omega$-m under irradiation). 
The first two requirements are of obvious reasons. The capability of selfhealing is critical to the blanket performance because unrepaired cracks allow electric currents to flow through the conducting structure. This can cause significantly higher pressure drop and unfavorably alter the velocity distribution in the coolant channels as well as flow distribution from the manifold to the connecting coolant channels.

The electrical insulation effectiveness of the coating is design dependent, and is characterized by the product $\rho_{c} t_{c}$ relative to $2 b M \rho$ where $\rho_{c}$ and $\rho$ are the electrical resistivities of coating material and liquid metal, respectively, $t_{c}$ is the coating thickness, and $2 b$ is the channel radial width.

The fully developed flow pressure gradient in a duct with insulator coating of uniform thickness $t_{c}$ can be derived analytically and is given by

$$
\frac{\mathrm{dp}}{\mathrm{dx}}=\frac{\sigma \mathrm{UB}^{2}}{1+\frac{\rho_{\mathrm{c}} \mathrm{t}_{\mathrm{c}} \mathrm{M}}{\rho_{\mathrm{c}} \mathrm{t}_{\mathrm{c}}+2 \mathrm{bM} \rho}}
$$

Figure 7 shows the dependence of pressure gradient on the ratio $\rho_{c} t_{c} / 2 b M \rho$. Twodimensional numerical analysis of MHD flow in a rectangular duct with insulator coating [8] gives similar results. In general, $\rho_{c} t_{c}$ should be at least five to ten times the value of $2 \mathrm{bM} \rho$. The present design requires $\rho_{\mathrm{c}} \mathrm{t}_{\mathrm{c}}$ to be at least $0.024 \Omega$ $\mathrm{m}^{2}$. The electrical resistivity of unirradiated $\mathrm{AlN}$ at $500^{\circ} \mathrm{C}$ is about $5 \times 10^{6} \Omega-\mathrm{m}$, and assume coating thickness of 10 microns, then $\rho_{c} t_{c} \sim 50$ which is 2000 times higher than the minimum requirement. The degradation of $\rho_{c}$ under the effects of radiation will reduce this margin. Experimental program is underway to define the radiation effects. 


\section{Effects of Uniform Cracks Through Insulator Coating.}

The insulator coating will probably be subjected to thermal cycling which may induce cracks through the coating. As discussed in section 4, unrepaired cracks could adversely affect the pressure drop and flow profiles. Fortunately the self-healing process can regenerate an AIN layer over the exposed aluminum-rich vanadium substrate. At present, quantitative data on the generation rate are being collected [9].

To study the effect on MHD pressure drop, it is assumed that the cracks are uniformly distributed over the duct wall surface, and that at any given time the regenerated layer inside the cracks has reached a certain fraction of the original coating thickness. Figure 8 shows the magnitude of the increase in pressure drop as a function of the crack fraction. The crack fraction is defined as the ratio of total crack area to total wall surface area. The regenerated layer thickness, $t$, is treated as a parameter in this analysis. It is seen that the increase in pressure drop is insignificant even for large crack fraction if thin layers of $1 / 100$ of the original coating thickness are formed inside the cracks.

\section{Conclusions}

The $\mathrm{V} / \mathrm{Li}$ poloidal blanket conceptual design meets both the MHD pressure and thermal hydraulic requirements with comfortable margins for power excursion. In the current design, heat removal by the supply channels is approximately $65 \%$ of the total heat deposition at the inboard. A more equalized heat removal function between the supply and return channels will enhance the 
MHD/thermal hydraulic performance. This can be achieved by optimizing the radial thickness of the channels.

Breeding blanket design is an ongoing ITER activity where design evolution and optimization will take place. Nevertheless, parametric study results presented in this paper appear favorable for a simple lithium-cooled blanket. Feasibility issues of the blanket are mainly related to material aspects such as the development of a reliable insulator coating or the demonstration of vanadium structural manufacturability. Data on self-healing of the coating material at relevant blanket temperatures are needed to quantify the adequacy of the coating material. Also radiation effects on the coating electrical resistivity are critical to the blanket performance. Significant R\&D efforts are being devoted to provide data for these issues during the ITER Engineering Design Activities. 


\section{References}

[1] P.-H. Rebut. Detail of the ITER Outline Design Report. The Fourth Meeting of The Technical Advisory Committee, San Diego Joint Work Site, January 10-12, 1994. ITER TAC-4-01.

[2] Y. Gohar. Design and R\&D for ITER First Wall, Blanket, and Shield. Blanket Working Group Meetings. Garching Joint Working Site, June 1993.

[3] T.Q. Hua and J.S. Walker. Three-Dimensional MHD Flow in Insulating Circular Ducts in Non-Uniform Transverse Magnetic Fields. Int. Journal of Engineering Sciences 27 (1989) 1079.

[4] J.S. Walker and G.S.S. Ludford. MHD Flow in Insulated Circular Expansions with Strong Transverse Magnetic Fields. Int. Journal of Engineering Sciences 12 (1974) 1045.

[5] T.Q. Hua, J.S. Walker, B.F. Picologlou and C.B. Reed. Three-Dimensional Magnetohydrodynamic Flows in Rectangular Ducts of Liquid-Metal-Cooled Blankets. Fusion Technology 14 (1988) 1389.

[6] T.Q. Hua and B.F. Picologlou. Magnetohydrodynamic Flow in a Manifold and Multiple Rectangular Coolant Ducts of Self-Cooled Blankets. Fusion Technology $19(1991) 102$.

[7] T.Q. Hua and B.F. Picologlou. Heat Transfer in Rectangular First Wall Coolant Channels of Liquid-Metal-Cooled Blankets. Fusion Technology 15 (1989) 1174. 
[8] L. Buhler and S. Molokov. Magnetohydrodynamic Flows in Ducts with Insulating Coatings. Kernforschungszentrum Karlsruhe GmbH, Karlsruhe, Report KfK-5103 (1993).

[9] K. Natesan. Argonne National Laboratory. Private communication (1994). 
Table 1. MHD Thermal Hydraulic parameters for the Inboard Breeding Blanket, 1800 MW Power

Total power to inboard blanket, MW

Inlet coolant temperature, ${ }^{\circ} \mathrm{C}$ 250

Outlet coolant temperature, ${ }^{\circ} \mathrm{C}$

Average flow velocity, $\mathrm{m} / \mathrm{s}$

Peak first wall temperature, ${ }^{\circ} \mathrm{C}$ 402

Coolant temperature at bottom, ${ }^{\circ} \mathrm{C}$ 288

Structural radial temperature difference at top, ${ }^{\circ} \mathrm{C}$ 96

Structural radial temperature difference at bottom, ${ }^{\circ} \mathrm{C}$ 39

Peak strongback temperature, ${ }^{\circ} \mathrm{C}$ 329

Volumetric flow rate, $\mathrm{m}^{3} / \mathrm{s}$ 5.50

Mass flow rate, $\mathrm{kg} / \mathrm{s}$ 2778

Pumping power, $\mathrm{MW}$

Total pressure drop, MPa

0.61 


\section{Figure Captions}

Fig. 1. Cross section of a blanket segment for the ITER breeding blanket.

Fig. 2. Three-dimensional MHD pressure drop in an insulating circular duct with a rapidly decaying transverse magnetic field. $M$ is the Hartmann number.

Fig. 3. Nuclear heating rate in the blanket for $1.2 \mathrm{MW} / \mathrm{m}^{2}$ average neutron wall loading.

Fig. 4. Total MHD pressure drop and pumping power for the inboard blanket.

Fig. 5. Peak vanadium temperatures at the first wall and back plate, and bulk exit coolant temperature for $250^{\circ} \mathrm{C}$ inlet temperature and $1800 \mathrm{MW}$ fusion power.

Fig. 6. Radial temperature difference between the peak first wall temperature and average back wall temperature at the top and bottom poloidal cross sections.

Fig. 7. Fully-developed flow pressure gradient in channels with insulator coatings whose effectiveness is characterized by the ratio $\rho_{c} t_{c} / 2 b M \rho$.

Fig. 8. Effects of cracks through the insulator coating, quantified by the crack fraction, on pressure drop relative to the initially crack-free scenario. A regenerated layer of thickness, $t$, has formed in the cracks, while $t_{c}$ is the original coating thickness. 


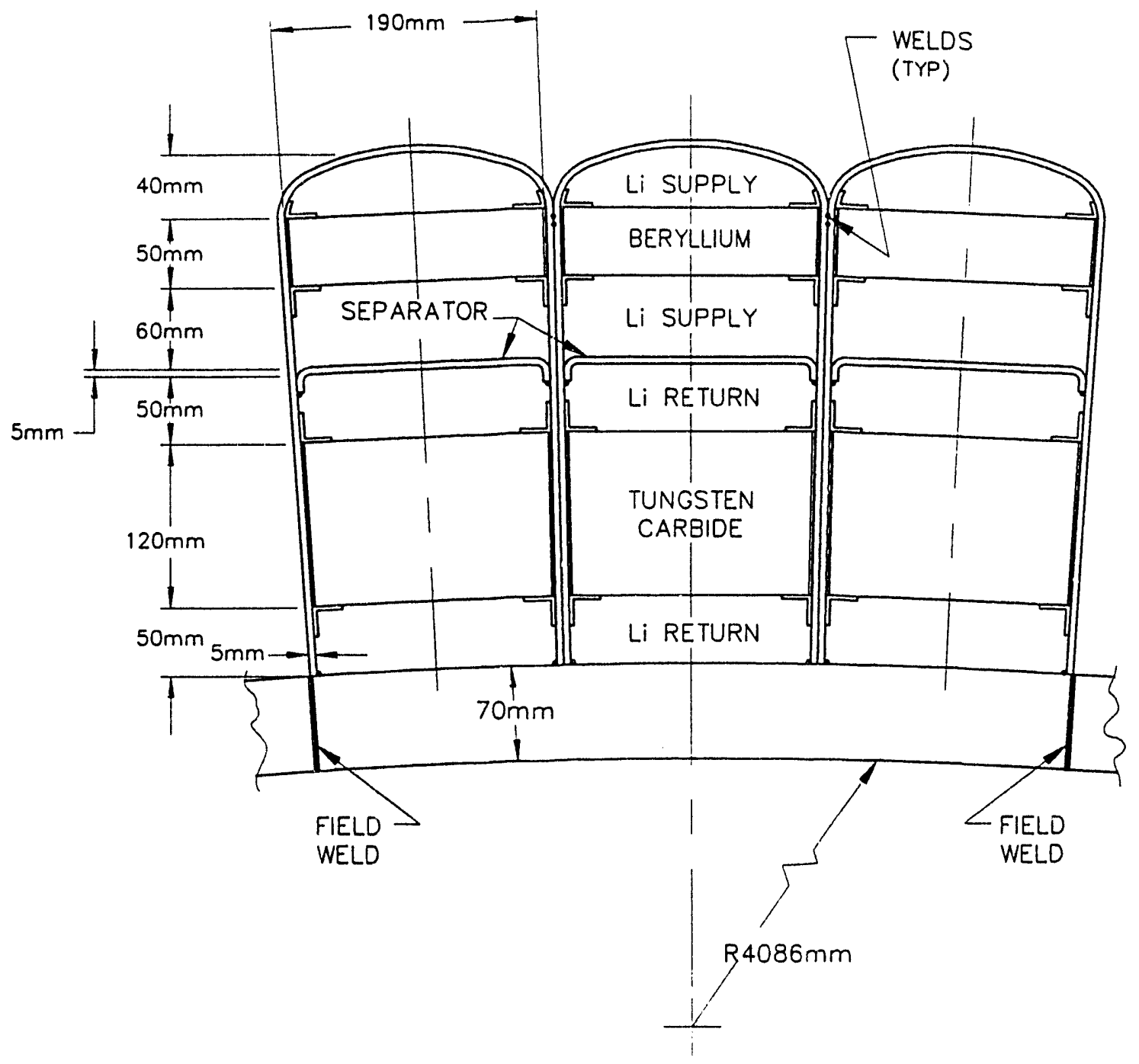

Figure 1

Thanh Q. Hua and Yousry Gohar MHD Pressure Drops \& Thermal Hydraulic Analysis for the ITER... 


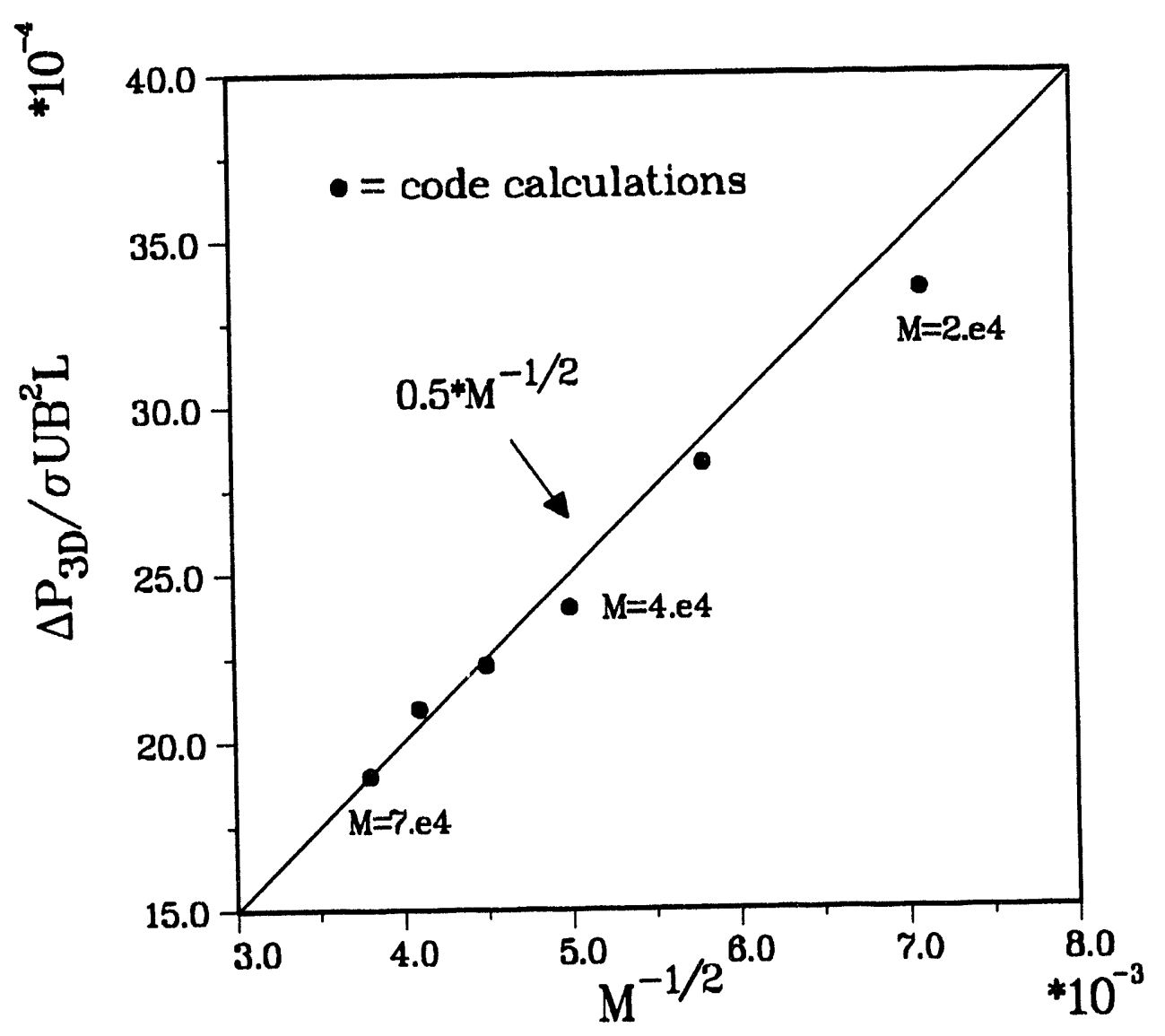

Figure 2

Thanh Q. Hua and Yousry Gohar MHD Pressure Drops \& Thermal Hydraulic Analysis for the ITER... 


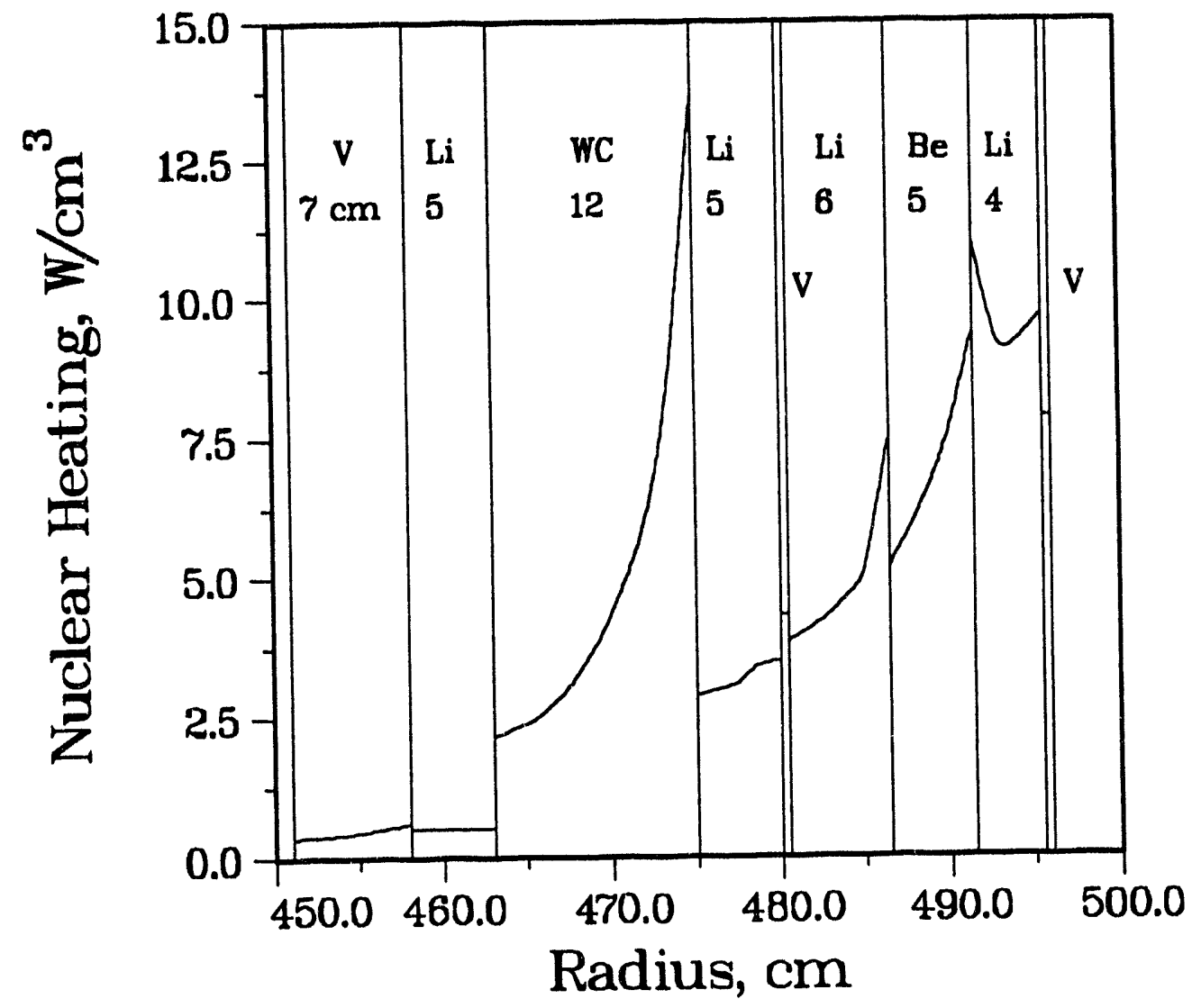

Figure 3

Thanh Q. Hua and Yousry Gohar MHD Pressure Drops \& Thermal Hydraulic Analysis for the ITER... 


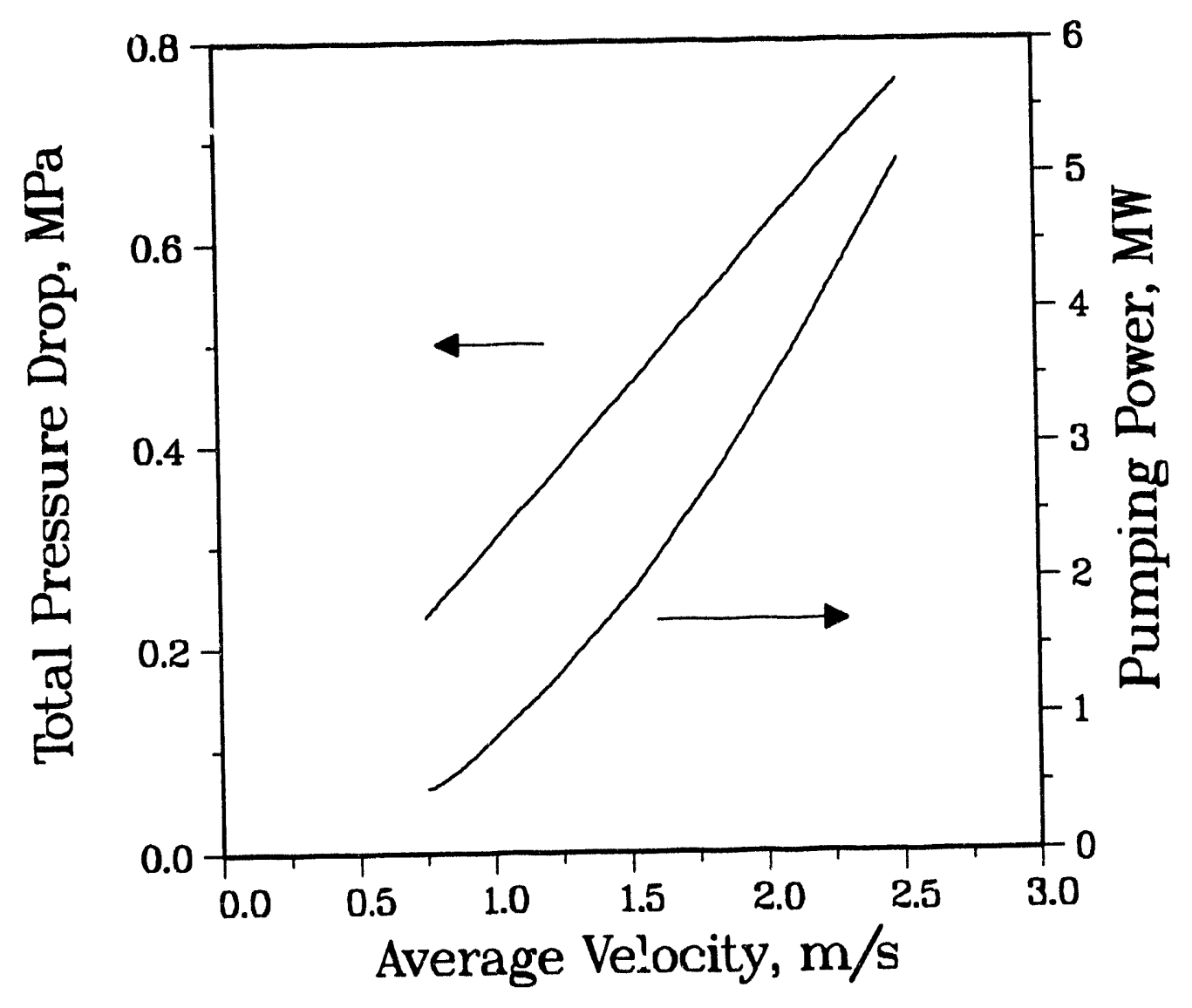

Figure 4

Thanh Q. Hua and Yousry Gohar MHD Pressure Drops \& Thermal Hydraulic Analysis for the ITER... 


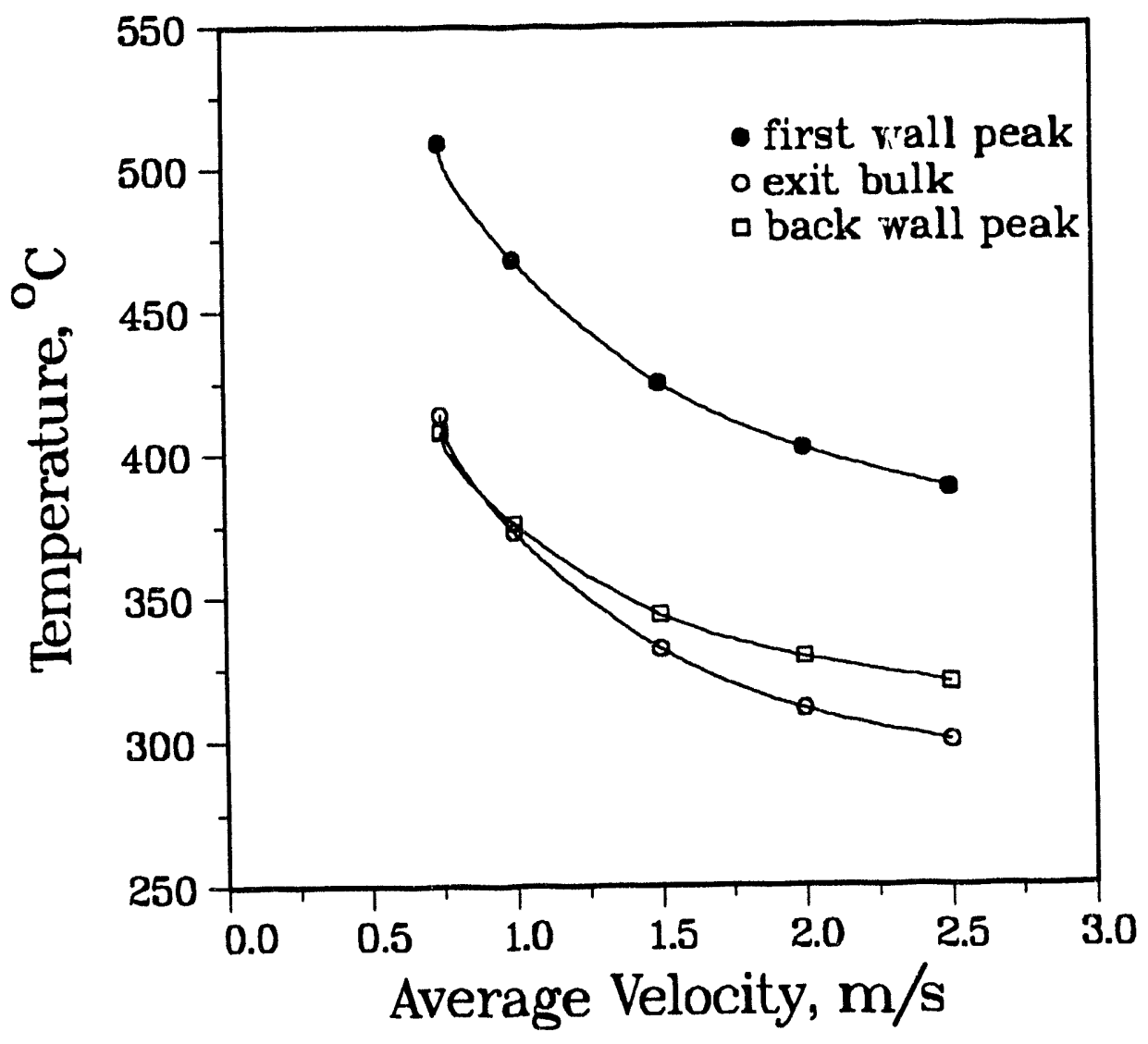

Figure 5

Thanh Q. Hua and Yousry Gohar MHD Pressure Drops \& Thermal Hydraulic Analysis for the ITER... 


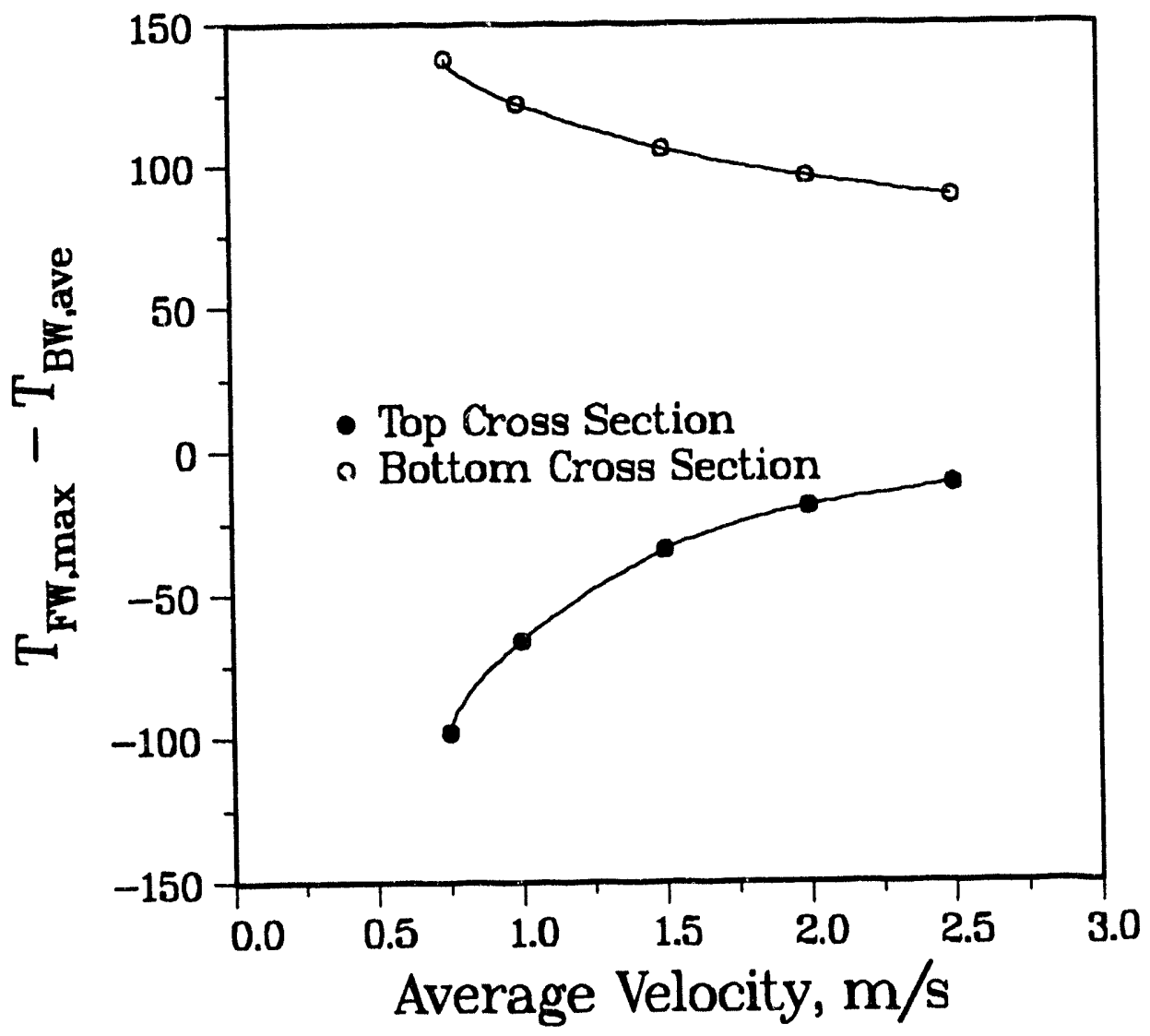

Figure 6

T.Q. Hua and Y. Gohar MHD Pressure Drops \& Thermal Hydraulic Analysis for the ITER.. 


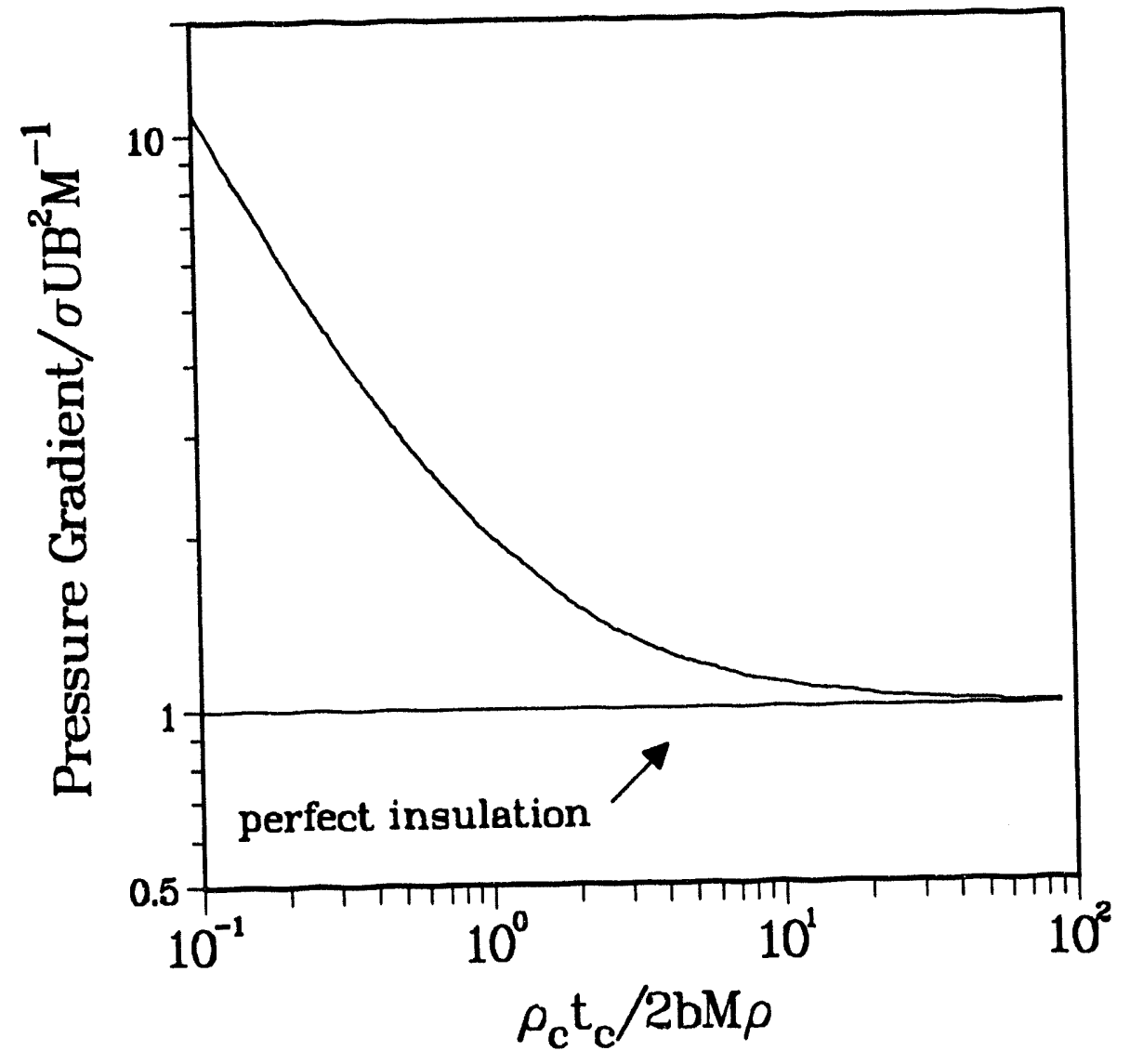

Figure 7

Thanh Q. Hua and Yousry Gohar MHD Pressure Drops \& Thermal Hydraulic Analysis for the ITER... 


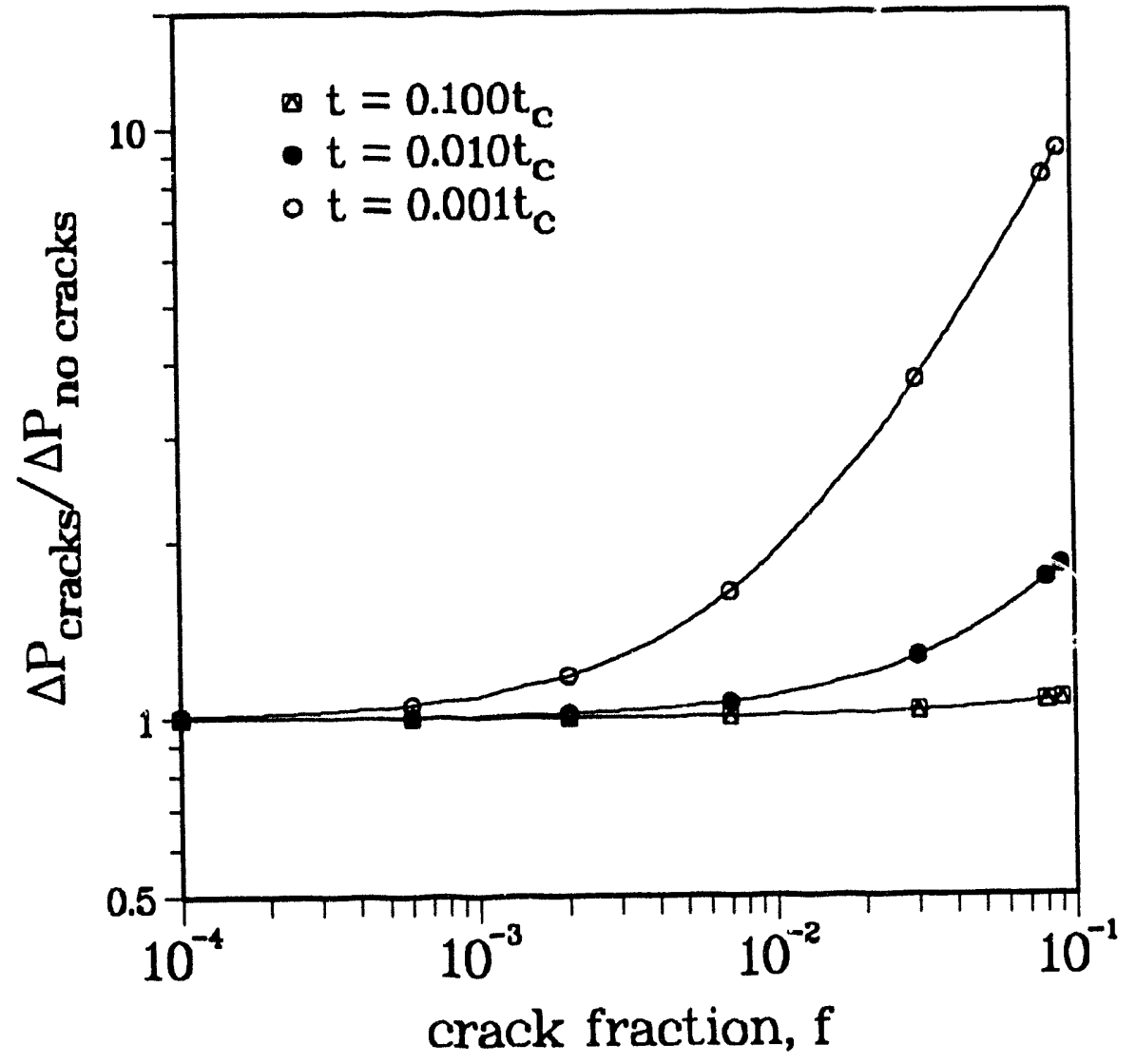

Figure 8

Thanh Q. Hua and Yousry Gohar MHD Pressure Drops \& Thermal Hydraulic Analysis for the ITER... 

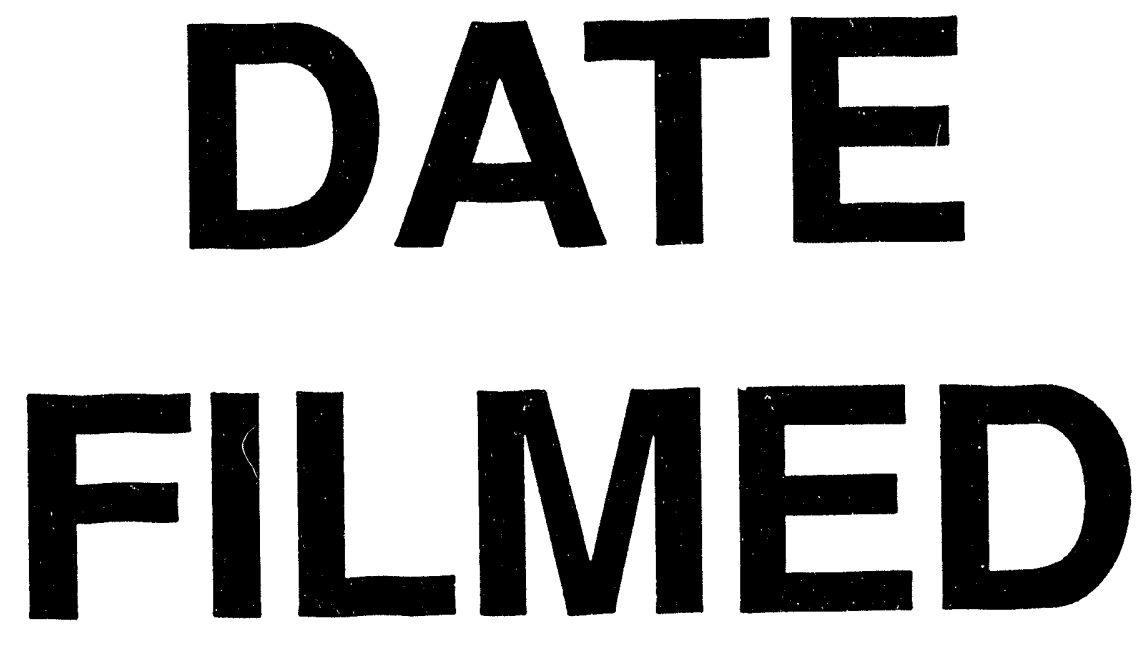

$8 / / 8 / 94$
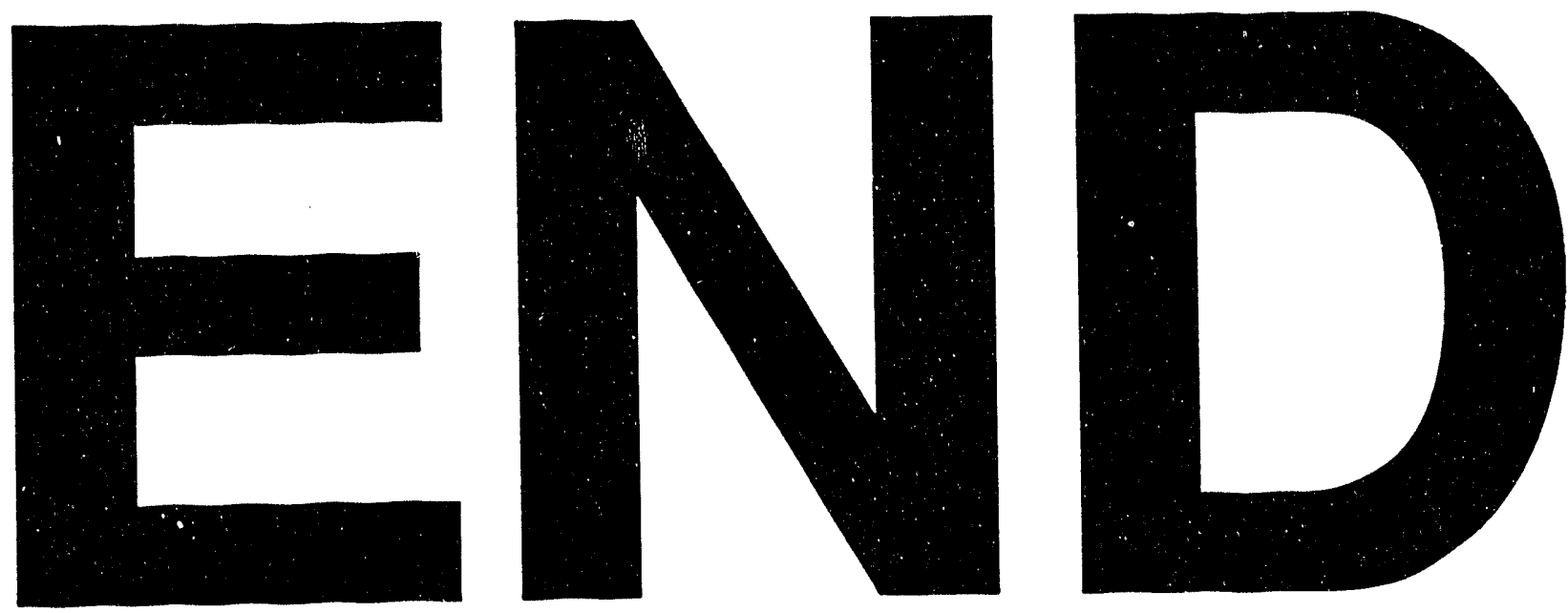
